Table 1

\begin{tabular}{|c|c|c|c|c|c|}
\hline \multirow[t]{2}{*}{ Baseline characteristics } & \multirow{2}{*}{$\begin{array}{c}\text { All patients } \\
(n=22196)\end{array}$} & \multicolumn{2}{|c|}{ Country stratum A } & \multicolumn{2}{|c|}{ Country stratum B } \\
\hline & & $\begin{array}{l}\text { TNFi mono } \\
(n=4940)\end{array}$ & $\begin{array}{c}\text { csDMARD + } \\
\text { TNFi }(n=2547)\end{array}$ & $\begin{array}{l}\text { TNFi mono } \\
(\mathrm{n}=9693)\end{array}$ & $\begin{array}{l}\text { csDMARD + } \\
\text { TNFi }(n=5016)\end{array}$ \\
\hline Age (years), mean (SD) & $42.6(12.5)$ & $43.4(12.0)$ & $42.8(12.2)$ & $41.6(12.7)$ & $43.7(12.7)$ \\
\hline Females, \% & 41.1 & 37.7 & 38.2 & 42.0 & 44.2 \\
\hline Disease duration (yrs), mean (SD) & $5.7(8.0)$ & $6.2(7.7)$ & $6.7(7.4)$ & $4.9(8.2)$ & $6.1(8.2)$ \\
\hline Enthesitis, \% & 50.3 & 16.7 & 33.9 & 57.8 & 59.7 \\
\hline SJC-28, median (IQR) & $0(0-1)$ & $0(0-0)$ & $0(0-2)$ & $0(0-0)$ & $0(0-2)$ \\
\hline VAS pain $(0-100)$, mean (SD) & $60.9(24.5)$ & $63.3(26.5)$ & $67.8(23.3)$ & $60.2(23.4)$ & $57.2(24.3)$ \\
\hline $\mathrm{CRP}(\mathrm{mg} / \mathrm{L})$, median (IQR) & $8(3-20)$ & $7.8(2-20)$ & $18(6.7-32.6)$ & $6.0(2.7-15)$ & $8.0(3-22)$ \\
\hline BASDAI (0-10), mean (SD) & $5.7(2.1)$ & $5.7(2.2)$ & $6.2(2.1)$ & $5.6(2.0)$ & $5.4(2.2)$ \\
\hline BASFI $(0-10)$, mean (SD) & $4.4(2.5)$ & $4.4(2.6)$ & $4.9(2.5)$ & $4.3(2.4)$ & $4.2(2.9)$ \\
\hline ASDAS, mean (SD) & $3.5(1.1)$ & $3.7(1.0)$ & $4.0(1.0)$ & $3.3(1.0)$ & $3.3(1.1)$ \\
\hline On Infliximab, \% & 25.7 & 21 & 22 & 24 & 36 \\
\hline \multicolumn{6}{|l|}{ Baseline csDMARD use, $\%$} \\
\hline -Methotrexate & & 0 & 45 & 0 & 63 \\
\hline -Sulfasalazine & & 0 & 68 & 0 & 33 \\
\hline -Leflunomide & & 0 & 8 & 0 & 1 \\
\hline
\end{tabular}

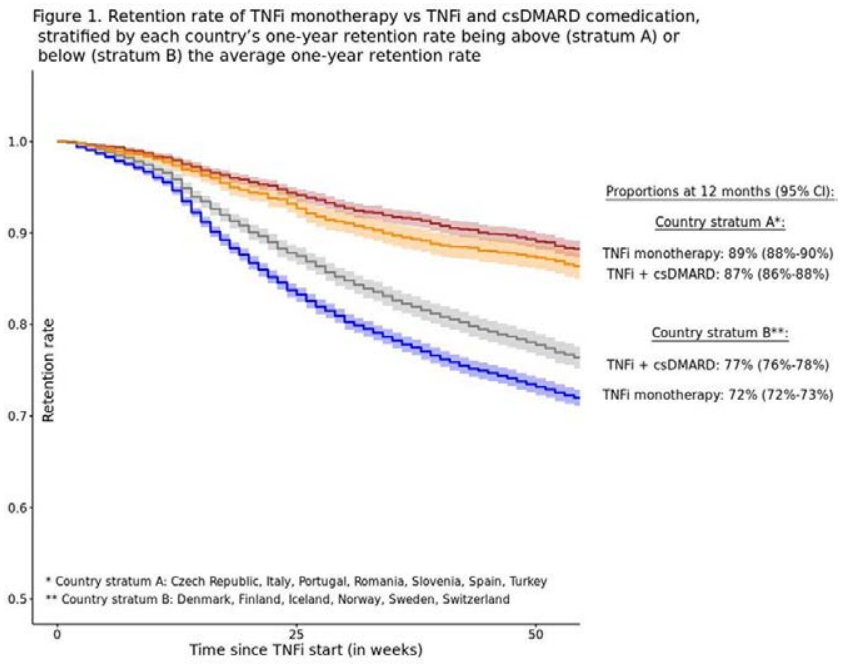

Anne Gitte Loft Grant/research support from: Novartis, Consultant of: AbbVie, MSD, Novartis, Pfizer and UCB, Speakers bureau: AbbVie, MSD, Novartis, Pfizer and UCB, Adrian Ciurea Consultant of: Consulting and/or speaking fees from AbbVie, Bristol-Myers Squibb, Celgene, Eli Lilly, Merck Sharp \& Dohme, Novartis and Pfizer., Dan Nordström Consultant of: Abbvie, Celgene, Lilly, Novartis, Pfizer, Roche and UCB., Speakers bureau: Abbvie, Celgene, Lilly, Novartis, Pfizer, Roche and UCB., Ziga Rotar Consultant of: Speaker and consulting fees from Abbvie, Amgen, Biogen, Eli Lilly, Medis, MSD, Novartis, Pfizer, Roche, Sanofi., Speakers bureau: Speaker and consulting fees from Abbvie, Amgen, Biogen, Eli Lilly, Medis, MSD, Novartis, Pfizer, Roche, Sanofi., Florenzo lannone Consultant of: Speaker and consulting fees from AbbVie, Eli Lilly, Novartis, Pfizer, Roche, Sanofi, UCB, MSD, Speakers bureau: Speaker and consulting fees from AbbVie, Eli Lilly, Novartis, Pfizer, Roche, Sanofi, UCB, MSD, Maria Jose Santos Speakers bureau: Novartis and Pfizer, Manuel Pombo-Suarez Consultant of: Janssen, Lilly, MSD and Sanofi., Speakers bureau: Janssen, Lilly, MSD and Sanofi., Björn Gudbjornsson Speakers bureau: Novartis and Amgen, Heřman Mann: None declared, Nurullah Akkoc: None declared, Catalin Codreanu Consultant of: Speaker and consulting fees from AbbVie, Accord Healthcare, Alfasigma, Egis, Eli Lilly, Ewopharma, Genesis, Mylan, Novartis, Pfizer, Roche, Sandoz, UCB, Speakers bureau: Speaker and consulting fees from AbbVie, Accord Healthcare, Alfasigma, Egis, Eli Lilly, Ewopharma, Genesis, Mylan, Novartis, Pfizer, Roche, Sandoz, UCB, Irene van der Horst-Bruinsma Grant/research support from: AbbVie, Novartis, Eli Lilly, Bristol-Myers Squibb, MSD, Pfizer, UCB Pharma, Consultant of: AbbVie, Novartis, Eli Lilly, Bristol-Myers Squibb, MSD, Pfizer, UCB Pharma, Brigitte Michelsen: None declared, Gary Macfarlane: None declared, Merete L. Hetland Grant/research support from: BMS, MSD, AbbVie, Roche, Novartis, Biogen and Pfizer, Consultant of: Eli Lilly, Speakers bureau: Orion Pharma, Biogen, Pfizer, CellTrion, Merck and Samsung Bioepis, Matija Tomsic: None declared, Burkhard Moeller: None declared, Pedro Ávila-Ribeiro Grant/ research support from: Novartis, Carlos Sánchez-Piedra: None declared, Heikki Relas Grant/research support from: Abbvie., Consultant of: Abbvie, Celgene, and Pfizer., Speakers bureau: Abbvie, Celgene, and Pfizer., Arni Jon Geirsson: None declared, Lucie Nekvindova: None declared, Gozde Yildirim Cetin Speakers bureau: AbbVie, Novartis, Pfizer, Roche, UCB, MSD, Ruxandra lonescu Consultant of: Consulting fees from Abbvie, Eli-Lilly, Novartis, Pfizer, Roche, Sandoz, Speakers bureau: Consulting and speaker fees from Abbvie, Eli-Lilly, Novartis, Pfizer, Roche, Sandoz, Niels Steen Krogh: None declared, Johan Askling Grant/ research support from: JA acts or has acted as PI for agreements between Karolinska Institutet and the following entities, mainly in the context of the ARTIS national safety monitoring programme of immunomodulators in rheumatology: Abbvie, BMS, Eli Lilly, Merck, MSD, Pfizer, Roche, Samsung Bioepis, Sanofi, and UCB Pharma, Bente Glintborg Grant/research support from: Grants from Pfizer, Biogen and Abbvie, Ulf Lindström: None declared DOI: 10.1136/annrheumdis-2020-eular.1804

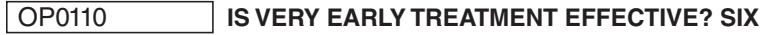 MONTHS RESULTS OF THE PREVAS STUDY, A PLACEBO-CONTROLLED TRIAL WITH ETANERCEPT IN PATIENTS SUSPECTED OF NON-RADIOGRAPHIC AXIAL SPONDYLOARTHRITIS}

T. Rusman $^{1}$, M. A. C. Van der Weijden ${ }^{2}$, M. T. Nurmohamed ${ }^{3}$, R. B. M. Landewé ${ }^{4}$, J. J. De Winter ${ }^{4}$, B. J. H. Boden ${ }^{5}$, P. M. Bet ${ }^{6}$, C. M. A. Van der Bijl ${ }^{1}$, C. J. Van der Laken ${ }^{1}$, I. Van der Horst-Bruinsma ${ }^{1} .{ }^{1}$ Amsterdam UMC location VUmc, Rheumatology, Amsterdam, Netherlands; ${ }^{2}$ Amsterdam UMC location VUmc, Amsterdam, Netherlands; ${ }^{3}$ Reade, Rheumatology, Amsterdam, Netherlands; ${ }^{4}$ Amsterdam UMC location AMC, Rheumatology, Amsterdam, Netherlands; ${ }^{5}$ Onze Lieve Vrouwe Gasthuis, Radiology, Amsterdam, Netherlands; ${ }^{6}$ Amsterdam UMC location VUmc, Clinical Pharmacology, Amsterdam, Netherlands

Background: Despite the new classification criteria for non-radiographic axial spondyloarthritis (nr-axSpA) patients according to the Assessment of Spondyloarthritis International Society (ASAS), there are limited data on disease progression in nr-axSpA patients.

Objectives: First to assess the improvement in disease activity in patients suspected of nr-axSpA after 16 weeks treatment with Etanercept (ETN) or Placebo (PBO). Second, to assess the changes of active inflammation on MRI of the SI-joints (SIJ) between the ETN and PBO group after 16 and 24 weeks without study medication.

Methods: The PrevAS study is a randomized, double blind, placebo-controlled trial with ETN performed in the VU University medical center (VUmc) (EudraCT number 2009-015515-40), with a screening period from 2009 until 2014. Patients suspected of nr-axSpA were included if they had chronic back pain for $\geq 3$ months, were $\geq 18$ years, fulfilled the Calin criteria of inflammatory back pain and had to be either HLA-B27 positive with at least $\geq 1$ Spondyloarthritis (SpA)-feature (as defined by the European Spondyloarthropathy Study Group (ESSG), or HLA-B27 negative with at least $\geq 2$ SpA-features and had a high disease activity score (Bath Ankylosing Spondylitis Disease Activity Index $\geq 4$ ) plus insufficient response to at least two NSAIDs. Excluded were patients who fulfilled the modified New York criteria for ankylosing spondylitis, or in case of previous biological use. Included patients were randomly assigned $(1: 1)$ for 16 weeks treatment with ETN $(\mathrm{N}=40)$ or PBO $(\mathrm{N}=40)$ and followed after the treatment period for 24 weeks. The primary endpoint was the number of patients achieving the ASAS20 response at week 16. MRI was performed at baseline, 16 and 24 weeks and scored using the Spondyloarthritis Research Consortium of Canada (SPARCC) index for number of active inflammatory lesions.

Results: The majority of included patients was female (63.8\%). Patient characteristics, like the presence of the HLA-B27 antigen and number of SpA-features 
at baseline, were comparable between the ETN and PBO group. Mean compliance to the study medication at sixteen weeks was $72.1 \%$. Longitudinal regression analysis over the first 16 weeks showed a trend towards a three times higher chance to achieve the ASAS20 response in the ETN compared to the PBO group $(\mathrm{OR}=3.2,95 \% \mathrm{Cl}[0.6 ; 16.7] p=0.18)$ (Figure 1). No differences were observed in ASAS20 response at 24 weeks. A positive SPARCC score (SPARCC $\geq 2.5$ ) of the SIJ was observed in the ETN and PBO group in 33.3\% (13/39 patients) vs. $30.8 \%$ (12/39 patients) at baseline, $16.7 \%$ (6/36 patients) vs. $17.5 \%(7 / 40$ patients) at 16 weeks and $21.9 \%$ (7/32 patients) vs. $20.0 \%$ (7/35 patients) at 24 weeks, respectively. Increased CRP-levels (CRP_UL $\geq 10.0 \mathrm{mg} / \mathrm{L}$ ) nor a positive SPARCC score at baseline, had significant influence on the ASAS20 response at 16 weeks follow-up. The safety profile was consistent with what is known for ETN in AS.

Conclusion: Patients suspected of nr-axSpA with high disease activity showed a trend towards a three times higher chance to achieve the ASAS20 response in the ETN group, compared to the PBO group at 16 weeks, regardless of a raised CRP level or positive MRI-SIJ at baseline.

Figure:

Longitudinal analysis ASAS20 response

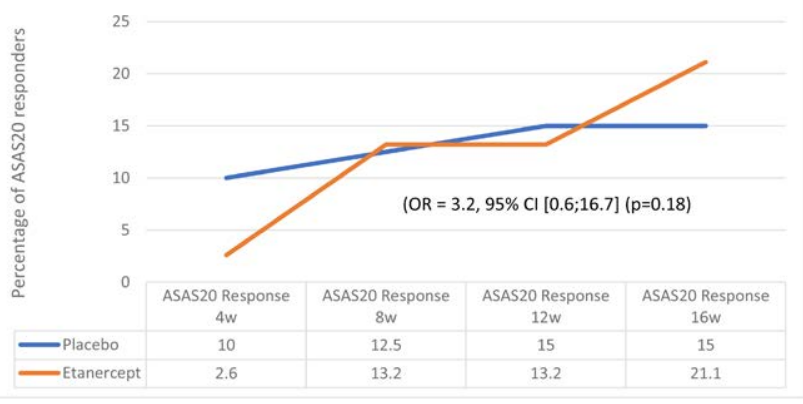

Acknowledgments: We thank Pfizer for financial support of this investigator initiated study. In addition we want to thank H. Hofman and W.A. ter Wee for practical study support.

Disclosure of Interests: Tamara Rusman: None declared, Mignon A.C. van der Weijden: None declared, Michael T Nurmohamed Grant/research support from: Abbvie, Bristol-Myers Squibb, Celltrion, GlaxoSmithKline, Jansen, Eli Lilly, Menarini, Merck Sharp \& Dohme, Mundipharma, Pfizer, Roche, Sanofi, USB, Consultant of: Abbvie, Bristol-Myers Squibb, Celltrion, GlaxoSmithKline, Jansen, Eli Lilly, Menarini, Merck Sharp \& Dohme, Mundipharma, Pfizer, Roche, Sanofi, USB, Speakers bureau: Abbvie, Bristol-Myers Squibb, Celltrion, GlaxoSmithKline, Jansen, Eli Lilly, Menarini, Merck Sharp \& Dohme, Mundipharma, Pfizer, Roche, Sanofi, USB, Robert B.M. Landewé Consultant of: AbbVie; AstraZeneca; Bristol-Myers Squibb; Eli Lilly \& Co.; Galapagos NV; Novartis; Pfizer; UCB Pharma, Janneke J. de Winter: None declared, B.J.H. Boden: None declared, Pierre M. Bet: None declared, Camile M.A. van der Bijl: None declared, Conny J. van der Laken: None declared, Irene van der Horst-Bruinsma Grant/research support from: AbbVie, Novartis, Eli Lilly, Bristol-Myers Squibb, MSD, Pfizer, UCB Pharma, Consultant of: AbbVie, Novartis, Eli Lilly, Bristol-Myers Squibb, MSD, Pfizer, UCB Pharma

DOI: 10.1136/annrheumdis-2020-eular.3472

\section{Rheumatoid arthritis - prognosis, predictors and outcome I}

\section{OP0111 \\ RHEUMATOID ARTHRITIS SEROLOGIC PHENOTYPE AT DIAGNOSIS AND SUBSEQUENT RISK FOR PNEUMONIA IDENTIFIED USING MACHINE LEARNING APPROACHES}

J. Sparks ${ }^{1}$, W. Huang ${ }^{1}$, B. Lu', S. Huang ${ }^{1}$, A. Cagan ${ }^{2}$, V. Gainer ${ }^{2}$, S. Finan ${ }^{3}$, G. Savova ${ }^{3}$, D. Solomon ${ }^{1}$, E. Karlson ${ }^{1}$, K. Liao ${ }^{1}$. ${ }^{1}$ Brigham and Women's Hospital, Boston, United States of America; ${ }^{2}$ Partners HealthCare, Boston, United States of America; ${ }^{3}$ Boston Children's Hospital, Boston, United States of America

Background: Patients with rheumatoid arthritis (RA) are at increased risk of serious infections, with considerable excess morbidity and mortality after pneumonia. RA-related autoantibodies such as anti-cyclic citrullinated peptide (CCP) and rheumatoid factor (RF) may be generated at inflamed pulmonary mucosa prior to clinical RA onset. Therefore, patients with seropositive RA may be at increased risk for pneumonia after RA diagnosis due to subclinical pulmonary injury.

Objectives: We investigated whether seropositive RA was associated with increased pneumonia risk compared to seronegative RA.

Methods: We performed a retrospective cohort study among RA patients seen at a health care system in Boston, MA. RA patients were identified using a previously validated electronic health record (EHR) algorithm incorporating billing codes, natural language processing (NLP) of notes, medications, and laboratory results at $97 \%$ specificity ${ }^{1}$. We constructed an incident RA cohort using NLP for the index date of initial mention of RA. All patients were required to have both CCP and RF data from clinical care to determine serologic RA phenotype. We used semi-supervised machine learning approaches to identify pneumonia using billing codes and terms extracted using NLP, with the Centers for Disease Control definition of pneumonia from medical record review as a gold standard. The area under the receiver operating curve (AUROC) for this billing code+NLP pneumonia algorithm was 0.94 compared to the standard rule-based pneumonia algorithm (billing code on inpatient discharge) AUROC of $0.86(p<0.001)$. Smoking status was extracted using NLP methods. Other covariates, including a previous validated weighted RA multimorbidity score ${ }^{2}$, were determined using structured EHR data. We used Cox regression to estimate hazard ratios (HRs) and 95\% confidence intervals (Cls) for pneumonia adjusting for potential confounders.

Results: We analyzed a total of 4,110 patients with incident RA and both CCP/ RF data available. Mean age at index date was 53.0 years (SD 14.8), $77.2 \%$ were female, and $79.8 \%$ were CCP+ or RF+. During 32,248 patient-years of follow-up (mean 7.8 years/patient), we identified 240 pneumonia cases. Patients with seropositive RA had a HR of $1.99(95 \% \mathrm{Cl} 1.30-3.01$, Table) for pneumonia compared to patients with seronegative RA, adjusted for age, sex, smoking, index year, ESR level, glucocorticoid use, DMARD use, and weighted RA multimorbidity score. While CCP+ RA (HR 1.91, 95\%Cl 1.23-2.97) and RF+ RA (HR $2.07,95 \% \mathrm{Cl} 1.35-3.16$ ) had increased pneumonia risk compared to seronegative RA, the CCP+RF- RA subgroup had no association with pneumonia (HR 0.67 , $95 \% \mathrm{Cl}$ 0.23-1.93).

Conclusion: Patients with incident seropositive RA, particularly RF+ RA, had increased risk for pneumonia throughout the RA disease course that was not explained by measured confounders including smoking status, multimorbidity, medications, and ESR level. Further studies should investigate how $\mathrm{RF}+$ may predispose RA patients to later develop pneumonia after clinical RA diagnosis.

Table. Hazard ratios for pneumonia by $\mathrm{CCP}$ and RF status among patients with incident RA $(n=4,110)$.

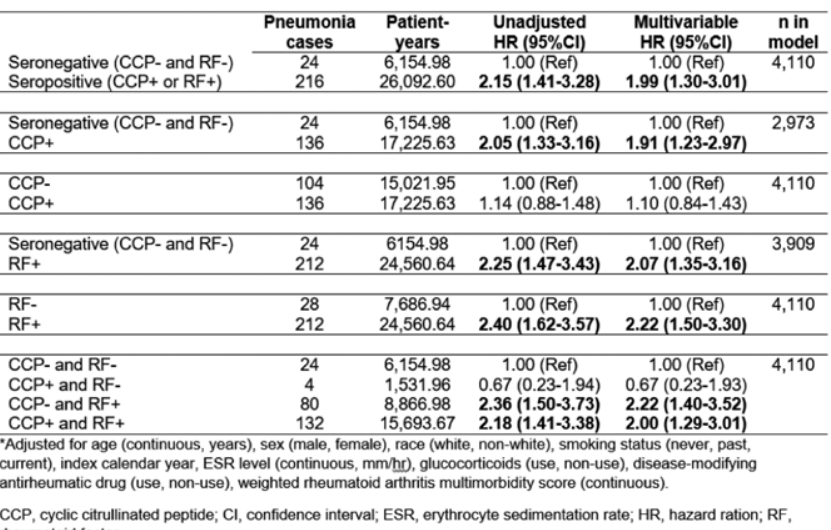

CCP, cyclic citrullinated peptide; $\mathrm{Cl}$, confidence interval; ESR, erythrocyte sedimentation rate; $\mathrm{HR}$, hazard ration; $\mathrm{R}$.

\section{References:}

[1] Liao KP, Cai T, Gainer V, et al. Electronic medical records for discovery research in rheumatoid arthritis. Arthritis Care Res. 2010;62(8):1120-1127.

[2] Radner H, Yoshida K, Mjaavatten MD, et al. Development of a multimorbidity index: Impact on quality of life using a rheumatoid arthritis cohort. Semin Arthritis Rheum. 2015;45(2):167-173.

Disclosure of Interests: Jeffrey Sparks Consultant of: Bristol-Myers Squibb, Optum, Janssen, Gilead, Weixing Huang: None declared, Bing Lu: None declared, Sicong Huang: None declared, Andrew Cagan: None declared, Vivian Gainer: None declared, Sean Finan: None declared, Guergana Savova: None declared, Daniel Solomon Grant/research support from: Funding from Abbvie and Amgen unrelated to this work, Elizabeth Karlson: None declared, Katherine Liao: None declared

DOI: 10.1136/annrheumdis-2020-eular.1900 